\title{
Emissions of unregulated pollutants from European gasoline and diesel passenger cars
}

\author{
Isabelle Caplain ${ }^{(1)}$, Fabrice Cazier* (2), Habiba Nouali ${ }^{(2)}$, Agnès Mercier ${ }^{(2)}$ \\ Jean-Claude Déchaux ${ }^{(1)}$, Valérie Nollet ${ }^{(1)}{ }^{\text {,Robert Joumard }}{ }^{(3)}$, Jean-Marc André ${ }^{(3)}$, Robert Vidon ${ }^{(3)}$ \\ (1) Physico-Chimie des Processus de Combustion et de l'Atmosphère \\ PC2A - UMR 8522 - FR CNRS 2416 CERLA- Université des Sciences et Technologies de Lille (USTL) \\ Bâtiment C11 - F. 59655 VILLENEUVE D'ASCQ Cedex \\ ${ }^{(2)}$ Centre Commun de Mesures, ULCO, MREI, 145 av. Schumann - F. 59140 Dunkerque \\ ${ }^{(3)}$ LTE : Laboratoire Transports et Environnement, INRETS, case 24, F. 69675 Bron cedex
}

\author{
Corresponding author: \\ Fabrice Cazier tél: +33(0)328658240/fax:+33(0)328658259 \\ e-mail adresses: cazier@univ-littoral.fr (Cazier Fabrice) or isabelle.caplain@univ-lille1.fr (Caplain Isabelle)
}

\begin{abstract}
:
Within the framework of the European Artemis project, the emissions of unregulated compounds were measured on new technology passenger cars. A sample of passenger cars was tested on a chassis dynamometer with constant volume sampling (CVS). The measurement of unregulated compounds comprised about 100 different VOC in the $\mathrm{C}_{2}-\mathrm{C}_{6}$ and $\mathrm{C}_{7}-\mathrm{C}_{15}$ range and carbonyl compounds. The sampling of these compounds was made using sorbent tubes followed by analysis with chromatography technology in liquid and gas phases. The influence of cold and warm starting conditions on the VOC composition was determined. The emission factors were determined and compared for either gasoline or diesel vehicles. The influence of the technology was evaluated and a first approach to understand the effect of recent technology on the ozone formation was developed.
\end{abstract}

Keywords: VOC, carbonyl compounds, speciated emissions, driving cycle, emission factor.

\section{Introduction:}

The transport sector is a major source of atmospheric pollutants. The Volatile Organic Compounds (VOC) result from incomplete combustion have a double influence on air quality. These molecules can act as primary toxic pollutants and play a role of precursor of the formation of photochemical-oxidant species.

Globally hydrocarbons emitted from vehicles are measured by THC analysers. In Europe few studies are carried out on the specified VOC (Schmitz. et al., 2000; Fontaine, 2000 ; Flandrin., 
2002) compared to the data concerning the regulated pollutants : See the state-of-the-art made some years ago in Europe (Hickman,1999).

The objective of this work is to improve the exhaust emission factors for the passenger cars by enlarging the emission factor database and by calculating emission factors according to the different purposes of the European Artemis project (Assessment and reliability of transport emission models and inventory systems). In the next future, in order to study the real impact of the automotive VOC emission, these improved emission factors will be used for atmospheric modelling, with the purpose to investigate its influence on the tropospheric ozone formation.

In this work, we describe the measurement of the speciated gas phase hydrocarbon and carbonyl emissions collected from recent technology passenger cars (ECE1504 to Euro 3) which represented the 2001 national French fleet. The vehicles used gasoline or diesel fuel, and measurements were made over the real-world test driving cycles and performed on a chassis dynamometer with constant volume sampling (CVS) at INRETS. The tailpipe emissions were sampled for light hydrocarbons $\left(\mathrm{C}_{2}-\mathrm{C}_{6}\right)$, semi-volatile hydrocarbons $\left(\mathrm{C}_{7}-\mathrm{C}_{15}\right)$ and aldehydes and ketones.

\section{Experimental}

\subsection{Vehicles and driving conditions}

The measuring program included 30 present passenger cars, i.e. 13 gasoline and 17 diesel fuelled cars. The vehicles conformed to emission standard ECE1504 to Euro 3. Table 1 shows the distribution per fuel and standard of the sample. The emission measurements were performed on the chassis dynamometer. The sample of vehicles was tested using a set of 4 real-world driving cycles (see Table 2): an "Inrets urbain fluide court" cycle repeated 15 times (15xIUFC) (Joumard et al, 1999), started firstly cold, then secondly warm, and 2 cycles "VP faible/forte motorisation" for urban and motorway driving behaviour (André, 2004). The latter cycles consist in alternative cycles, specific to vehicles with low or high powers 
respectively. The 2 15xIUFC cycles allow us to determine the excess emissions due to cold start. Both "VP" cycles show the emission for urban and motorway driving behaviour.

\subsection{Sampling}

The exhaust gas from vehicle is diluted with filtered ambient air using a constant volume sampler (CVS) device (Figure 1). VOC are sampled in the dilution tunnel using sorbent tubes: Carbotrap B and C, Carbosieve III for "light" hydrocarbons $\left(\mathrm{C}_{2}-\mathrm{C}_{6}\right)$ and Tenax for semi-volatile hydrocarbons $\left(\mathrm{C}_{7}-\mathrm{C}_{15}\right)$. The sampling was optimized by the use of two cartridges in series. During the first tests, this experiment showed that 25 to $30 \%$ of light and 40 to $60 \%$ of semi-volatile hydrocarbons are sampled on the second cartridge. By decreasing the sampling flow rate (Table 3) we reduced the breakthrough rate respectively up to $(18 \%)$ and $(30 \%)$. Before each sampling of exhaust gas a background contribution of the air dilution was recorded. For the collection of the aldehydes and ketones the diluted exhaust gas is pulled through a DNPH coated silica cartridge. After sampling, the cartridges are transported to the analysis laboratory in a temperature controlled container at $0^{\circ} \mathrm{C}$ and are stored at $-10^{\circ} \mathrm{C}$ before analysis.

\subsection{Analysis}

\section{Regulated pollutants measurement}

The measurement of the regulated pollutants was achieved at INRETS by means of usual analytical techniques (non-dispersived infrared for $\mathrm{CO}$ and $\mathrm{CO}_{2}$, chemiluminescence for $\mathrm{NOx}$ and flame ionisation detection for total hydrocarbons ).

\section{Unregulated pollutants measurement}

Carbotrap and Tenax samples were analysed by the thermal desorption preconcentration method, followed by quantification by high resolution gas chromatography with a flame ionisation detector (GC/FID) for compounds from $\mathrm{C}_{2}$ to $\mathrm{C}_{6}$ and with a mass spectrometer detector (GC/MS) for the compounds from $C_{7}$ to $C_{15}$. For light hydrocarbons we used the thermal desorption system (Turbomatrix TD Perkin Elmers) using two stage desorption. In the first stage the analytes were desorbed with a nitrogen flow from sample tube then refocused 
onto a narrow bore cold trap kept at $-30^{\circ} \mathrm{C}$ and filled with adsorbents, in the second one the trap was heated at $300^{\circ} \mathrm{C}$ to release materials into the chromatograph (Figure 2). In the case of hydrocarbons from $\mathrm{C}_{7}$ to $\mathrm{C}_{15}$, the adsorbed substances are concentrated in a desorption chamber at $220{ }^{\circ} \mathrm{C}$, before to be inject onto the beginning of the cold column chromatograph. (Module Combi Injector/Desorber EM640 Brüker). The thermal desorption and chromatographic conditions used for speciation of emissions samples are summarized in Table 4. The multiple gradient column temperature conditions were selected as a compromise between maximum peak resolution and minimum analysis time. Materials used for compound identification and quantification were purchased from Scotty (hydrocarbon standard gases) and Sigma-Aldrich (hydrocarbon standard liquids). Gas standards were prepared by injection of gases from Scotty cans (or liquid for example: BTEX ) into a 10 litre dilution round bottom flask under vacuum $(0-760 \mathrm{mmHg}$ at room temperature). These standards were diluted to the desired concentration, by filling the flask with nitrogen, then sampled on Tenax and Carbotrap cartridges by pumping (variation of the flow rate, variation of the sampling time to build the calibration curve). Hydrocarbons identifications were assigned by comparing retention times of chromatographic peaks from emissions samples with those from standard mixtures and by comparing mass spectra with those contained in NIST and/or WILEY libraries. The $\mathrm{C}_{2}-\mathrm{C}_{15}$ range of our identified compounds library contains 75 major species (26 alkanes, 9 alkenes/alkynes, 24 monoaromatics, 3 polyaromatics) (Table 5 and 6).

\section{Carbonyl compounds measurement}

Carbonyl compounds collected in the DNPH cartridge were eluted with $2 \mathrm{ml}$ of HPLC grade acetonitrile and analysed by HPLC (Spectra Physics P4000) with UV detection at $365 \mathrm{~nm}$ ((Spectra Focus 3000). A $4.6 \times 250 \mathrm{~mm} \mathrm{C18}$ column (Alltima, Altech) was used and the gradient elution was describes as follows in Table 7. Identification and quantification were made based on matching the HPLC retention time with those of authentic standards purchased to Supelco (réf 476 72-U -13 hydrazones) and using a weighted amounts of the authentic 
hydrazone standards. The 13 compounds identified are given in the Table 8 and contains 11 aldehydes and 2 ketones.

The detection limits were estimated for all characterised compounds analysed by GC and HPLC. Curves of calibration were established for the quantification of each identified species and a minimum of concentration was defined for the detected compounds in order to be introduced into the database (Table 8 and 9). The determination of these minimum values is based on the sensitivity of the analytical methods used.

\section{Results and Discussion}

The results of the exhaust gas speciation and the exhaust emission factor for each specy and each vehicle category are reported below. The influence of the driving cycle and technology on the emissions are discussed too.

\subsection{Families compounds characterised in the exhaust gas}

The different family's compounds characterised by GC and HPLC analysis are alkanes, alkenes, alkynes, aromatics and carbonyls compounds. The major VOC group emitted by the different passenger cars are the aromatic compounds and the alkanes. The results of this study show that amongst the total gas phase non methane hydrocarbons emitted for a gasoline engine, 75-93\% were accounted for aromatics species, 6-18\% for linear and substituted alkanes, $1.2-4.3 \%$ for alkenes and alkynes, and $0.1-2 \%$ for carbonyls compounds. And for a diesel engine $54-75 \%$ of species analysed are aromatics, 18-31\% linear and substituted alkanes, 3-6 \% alkenes and 2-6.4\% carbonyls compounds. The Table 10 shows the emission factors (in $\mathrm{mg} \mathrm{km}^{-1}$ ) of the different compounds for gasoline and diesel vehicles and for the different cycles. We observed an evolution of the species in the different families: For the carbonyl compounds, the major compounds detected are formaldehyde, acetaldehyde and ketone which account for approximately $73 \%$ of the total carbonyl emissions in the case of cold / warm starting. In the case of cars with diesel engines the proportion of these species is most important, it's relative to the fuel itself. The fractions of alkanes trapped on the cartridges include linear and substituted chains of carbons from $\mathrm{C}_{3}$ to $\mathrm{C}_{16}$ for the two types of 
technology. Concerning the diesel cars, some compounds with a chain length higher to 16 carbons are clearly identified (nonadecane, octadecane, heptadecane) compounds which are not found in the emission of gasoline cars. Cis-2-butene and 1-pentene are majors' alkenes and alkynes emitted by the vehicles. For the aromatic family, the more abundant compounds are 2-, 3-, and 4- ethyltoluene and $\mathrm{m}-$, $\mathrm{p}$ - xylene. Whatever the cycle is, the emission factor of gasoline cars are 10 times higher than the emission factor of diesel vehicles. In the case of diesel cars, some traces of polyaromatics species (PAH) are also qualitatively detected as 1and 2- methylnaphtalene. But those species were not quantified in this part of the study, and are reported by (Paturel et al., 2004). Whatever the cycle is, the emission factor of gasoline cars is 10 times higher than the emission factor of diesel vehicles. Globally, a most important emission of VOC is observed with gasoline vehicles compared to the diesel ones, especially in the case of the cold $15 x$ IUFC cycle. Generally, whatever vehicle technology and cycle are, aromatics compounds are the majority with a somewhat weaker part concerning the diesel compared to the gasoline cars. Saturated hydrocarbons comes second, according weaker percentages which are about $20 \%$ for diesel cars and $12 \%$ for gasoline cars. Concerning the carbonyl compounds, their own percentage is very low $(0.5 \%$ for gasoline and $10 \%$ for diesel).

\subsection{Influence of driving cycle}

In this part, we observe the influence of the driving cycle on the emission factor for the gasoline and diesel passenger vehicles. It should be noted that the emission factor for total VOC in the case of the cold $15 x$ IUFC cycle of the gasoline cars is largely higher than in the case of diesel cars.

Hot pollutant emissions are higher in the "VP" urban cycle than in the "VP" motorway cycle the ratio emission factor is approximately 4 for the diesel and 4.5 for the gasoline cars. For the alkanes, the emission factors on the hot "VP" urban cycle are higher for the gasoline cars than for the diesel ones. On contrary, the variation of emissions from gasoline to diesel cars are weak, generally speaking, as far as the motorway cycle is concerned. Between urban and 
motorway driving cycles, the emissions are generally, for the different VOC families, most important in the urban one (Figure 3). It's in relation with the characteristics of the cycle (mean speed, maximum speed, acceleration rate, etc) because in the case of motorway type, the speed profile is more regular.

\subsection{Influence of cold and hot starts on the emissions}

The influence of cold or warm start conditions on the VOC composition was determined by the difference of the emission obtained during the cold 15xIUFC and hot 15xIUFC cycles. Globally, the emission is the most important for the cold 15xIUFC cycle as we can observed on the Figure 4. In the case of vehicles with gasoline engine the amount of aromatic compounds are 4.2 times more important in a cold start than a warm one, alkanes are twice more, alkenes 2.8, light substituted alkanes 3.1, and carbonyls compounds are emitted in the same proportion. For the diesel engine, the amount of aromatic compounds are in average 2.2 time more important in a cold start than a warm one, alkanes in average 1.5 more, alkene in average 1.6, and carbonyls compounds in average 1.18 time more important. Concerning the alkanes, the variation from cold to hot start is more important for the gasoline passenger cars than for the diesel ones. Hydrocarbons with more than sixteen carbons were identified and quantified on the hot $15 x \mathrm{xIUFC}$ cycle for diesel engine, i.e. nonadecane $\left(22.1 \mathrm{mg} \mathrm{km} \mathrm{km}^{-1}\right)$, octadecane $\left(13.4 \mathrm{mg} \mathrm{km}^{-1}\right)$ and heptadecane $\left(9.4 \mathrm{mg} \mathrm{km}^{-1}\right)$. Those compounds are not found in the emissions of gasoline passenger cars. During the cold start phase, the aromatic compounds and alkenes are emitted in high proportion compared to the warm start phase with gasoline and diesel cars. The total VOC emission factor for the cold start is higher for gasoline vehicles $\left(7.2 \mathrm{~g} \mathrm{~km}^{-1}\right)$ compared to diesel ones $\left(0.88 \mathrm{~g} \mathrm{~km}^{-1}\right)$.

\subsection{Influence of the emission standard}

All the vehicles are characterised by an emission standard regulation. The regulation follows the European standard. The gasoline vehicles comply with Euro 1 to Euro 3 standard, the diesel ones with ECE1504 to Euro 3. In the case of gasoline engine, when we compared the different standards we noticed that the emission factors of aromatic compounds decreased 
from Euro 1 to Euro 3 for "VP" urban and motorway driving cycles, which is the contrary of the cold start behaviour (Figure 5). In the case of diesel engines the emission factors for the same category of compounds are going up and down, i.e. for the cold $15 x$ IUFC cycle the emission factor of aromatics compounds are for ECE1504, Euro 1, Euro 2 and Euro 3 resp. $0.75,0.08,2.25$ and $0.75 \mathrm{~g} \mathrm{~km}^{-1}$. For all driving cycles the highest emission is generally observed in Euro 2 standard, this for all families of compounds detected. The Figure 6 shows the evolution of the different compounds according to the European standard during the "VP" urban and motorway driving cycles. In the case of aldehydes, a decrease of the emission factors from ECE1504 to Euro 3 technology for gasoline and diesel fuel cars was observed. Alkanes have the same behaviour for the gasoline car but the emission increase with the standard for diesel cars and alkanes with a chain length up to 15 carbons increase too. For the others species, the evolution of emission factors with the regulation was not clearly defined, the figures were going up and down.

\subsection{Perspective of the project}

After the evaluation of the different unregulated compounds, the result of the analysis will served to establish a database of representative emission factors for different European passenger car classes. This database could have a lot of application for the atmospheric pollution. Certain species are more polluting as much in terms of toxicity as in ozone formation potential.

In terms of toxicology, U.S EPA have established a list of Mobile Source Air transport compounds composed with the following species : acetaldehyde, acrolein, benzene, 1,3 butadiene, ethylbenzene, formaldehyde, n-hexane, toluene, xylene. The European data base will allow to improve the knowledge of these compounds, which were detected and measured in different driving cycles.

The impact of the different compounds on the ozone formation potential could be evaluated. and the data base could be used for atmospheric modelling. The ozone formation potential could be evaluated by a reactivity scale like the MIR (Maximum Incremental Reactivity) 
(Carter, 1994). Applied under optimal California weather conditions which differ from the usual European climatic conditions, however, this potential can be used as an indicator for comparing the impact of the individual VOC emissions on the ozone formation for various types of vehicles. For the Artemis project, we can evaluated the major compounds by family able to produce ozone:

- Aldehyde: formaldehyde $\left(<0,035 \mathrm{~g} \mathrm{O}_{3} / \mathrm{g}\right.$ VOC $)$, acrolein $\left(0,015 \mathrm{~g} \mathrm{O}_{3} / \mathrm{g} \mathrm{VOC}\right)$ and acetaldehyde (0,04 g O3 / g VOC).

- Alkene and Alkyne : cis -2- butene, 1-pentene and trans-2-butene

- Alkane: undecane, tetradecane, tridecane, nonane, dodecane, decane and isobutane.

- Aromatics : m- and p- xylene, 2-, 3-, 4- ethyltoluene, 1,3,5 trimethylbenzene and 1,2,4 trimethylbenzene.

With our measurements, the "VP" urban driving cycle and the cold urban start produced a lot of ozone. This study could be a preliminary step for atmospheric modelling, with the purpose to investigate its influence on the tropospheric ozone formation.

\section{Conclusions}

The unregulated emissions of various vehicles representing the 2001 French passenger car fleet were measured on real-world driving cycles. Combining the three sets of speciation data provided a profile of the gas phase hydrocarbons emissions for gasoline and diesel fuel. The emission factors were determined for all the species and for the different driving cycles. The results show the influence of the specific conditions of each driving cycle and the impact of new technology on the global emission. Whatever the driving cycle is, the decrease of unit emissions from Euro 1 to Euro 3 standards is almost systematic for aromatic compounds; Diesel vehicles always appear less polluting than gasoline ones. The comparison between cold and hot starts was performed in order to study more precisely the impact of the automotive VOC emissions in an urban site. In the next future the database will be used for atmospheric modelling, with the purpose to see the influence on the ozone formation. 
All these data are currently processed again but with all emission measurements of unregulated pollutants carried out or collected within the Artemis project, in order to derive the emission factors of these pollutants in the next European Artemis inventorying tool for the transport means, which should be available by Spring 2005.

\section{Acknowledgements}

This study was carried out within the $5^{\text {th }}$ framework programme of the European Community with the Artemis project concurrently supported by ADEME, the French environment agency.

\section{References}

André, M., Joumard R., 2004). Real-world and specific to vehicle driving cycles for measuring car pollutant emissions. 13th Int. Symp. "Transport and Air Pollution", Sept. 13-15, Boulder, Colorado USA, proceedings, NCAR, Boulder, p. 115-124.

André, M., 1998. Construction de cycles de conduite représentatives pour la mesure des émissions de polluants des véhicules (building-up of representative driving cycles for vehicle pollutant emission measurement). Thèse de l'Institut National des Sciences Appliquées de Lyon, INRETS, Bron, France, 278 p.

Carter, W.P.L, 1994. Development of ozone reactivity scales for volatile organic compounds. Journal of the Air and Waste Management Association, vol 44, pp881-899.

Flandrin, Y., Vidon, R., Tassel P., Déchaux, J.C, Nollet, V., Cazier, F. and Joumard, R., 2002. Mesure des émissions automobiles de composés organiques volatils et de dérivés carbonylés (Measurement of the car emissions of volatile organic compounds and carbonyls). INRETS report, Bron, France, ${ }^{\circ}$ LTE 0210, 269 p.

Flandrin Y, 2002. Mesure des émissions automobiles de composés organiques volatils et de dérivés carbonyls; application à la modélisation eulérienne de la pollution atmosphérique 
(Measurement of the car emissions of volatile organic compounds and carbonyls; application to the eulerian modelling of air pollution). PhD report, Univ. Scient. Tech. Lille, 6 mars. 2002.

Fontaine, H., 2000. Les composés organiques volatils dans les gaz d'échappement des automobiles : établissement de profils d'émission représentatifs de différentes conditions de condite (Volatils organics compounds in the automotive exhaust: establishment of representated emissions profil of different driving cycles). Thèse Université de Compiègne, France, 366 p.

Hickman, J.D, Joumard, R., Hassel, D., Samaras, Z., Sorenson, S., 1999. MEET Methodology for calculating transport emission and energy consumption. European commission DG VII ISBN 92-828-6785-4, Luxembourg, 362 p.

Joumard, R., André, M., Vidon, R., Tassel, P. and Pruvost, C., 1999. Influence du cycle de conduite sur les émissions unitaires de polluants des voitures particulières (Influence of driving cycles on unit emissions of atmospheric pollutants from passenger cars). INRETS report, $\mathrm{n}^{\circ}$ LTE 9902, Bron, France, 122 p.

Joumard, R., André, J.M. ,Caplain, I., Paturel, L., Cazier, F., Mercier, A., Combet, E., Devos, 0., Nouali, H., Vidon, R., Tassel, P., Perret, P., Lacour, S., Hugot, M., Déchaux, J.C., 2004. Campagne de mesure des émissions unitaires de polluants non réglementés des véhicules particuliers (Measurement campaign of unit emissions of non-regulated atmospheric pollutants from passenger cars). Inrets report, Bron, France, $\mathrm{n}^{\circ} \mathrm{LTE}$ 0408, $151 \mathrm{p}$.

Schmitz, T., Hassel, D., and Weber, F.J., 2000. Determination of VOC component in the exhaust of gasoline and diesel passenger cars. Atmospheric Environment 34, Issue 27, p 4639-4647.

Shauer, J.J., Kleeman, M.S., Cass, G.R. and Simoneit, B.R.T, 2002. Measurement of emissions from air pollution sources C1-C31 organic compounds from gasolinepowered motor vehicles. Environmental Science and Technology 36, 1169-1180. 


\section{Figures:}

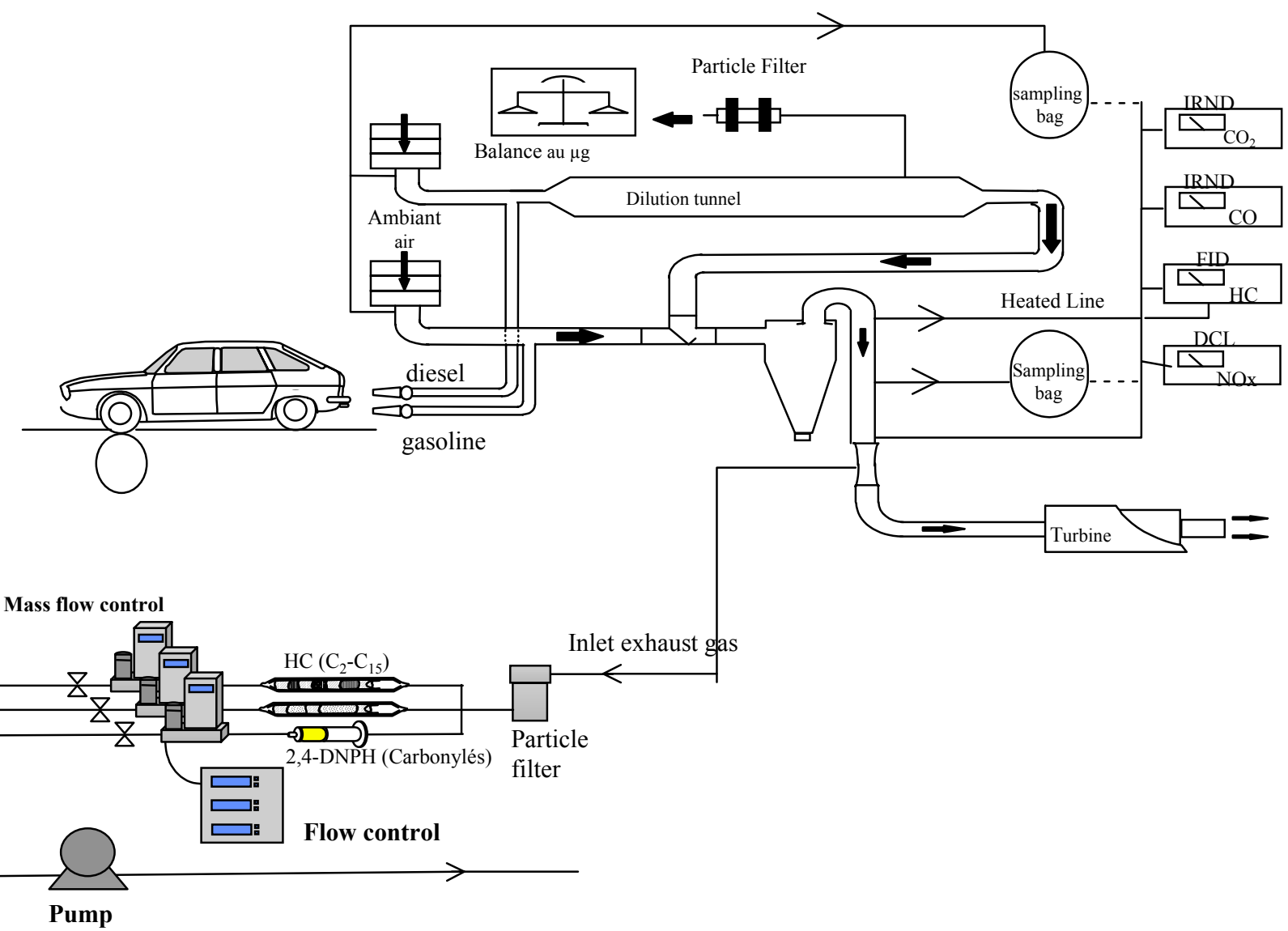

Figure 1. Chassis dynamometer with Constant Volume Sampling (CVS) with the scheme of the analysis for unregulated compounds.

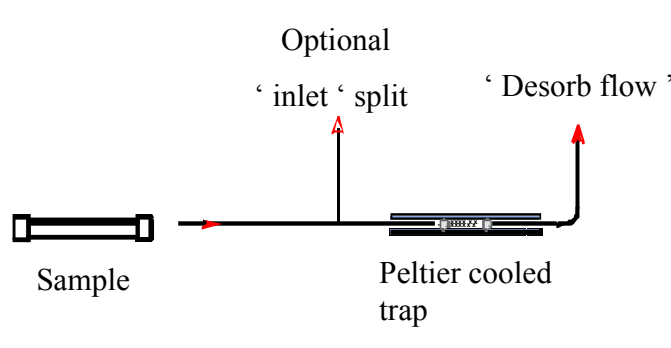

cartridge desorption of sample

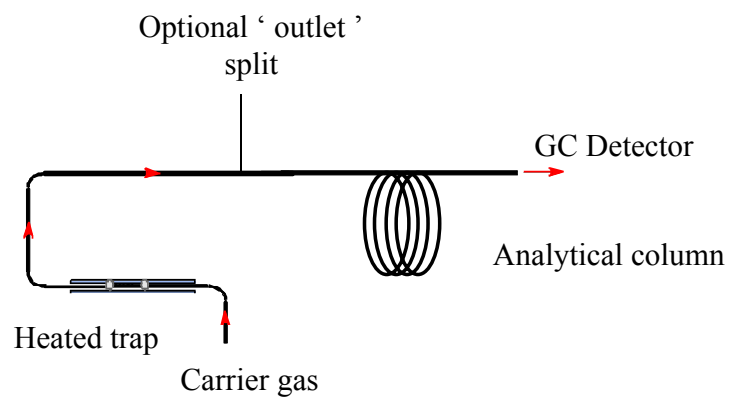

cold trap desorption

Figure 2 : Thermodesorption of cartridge follow by GC/FID analysis. 


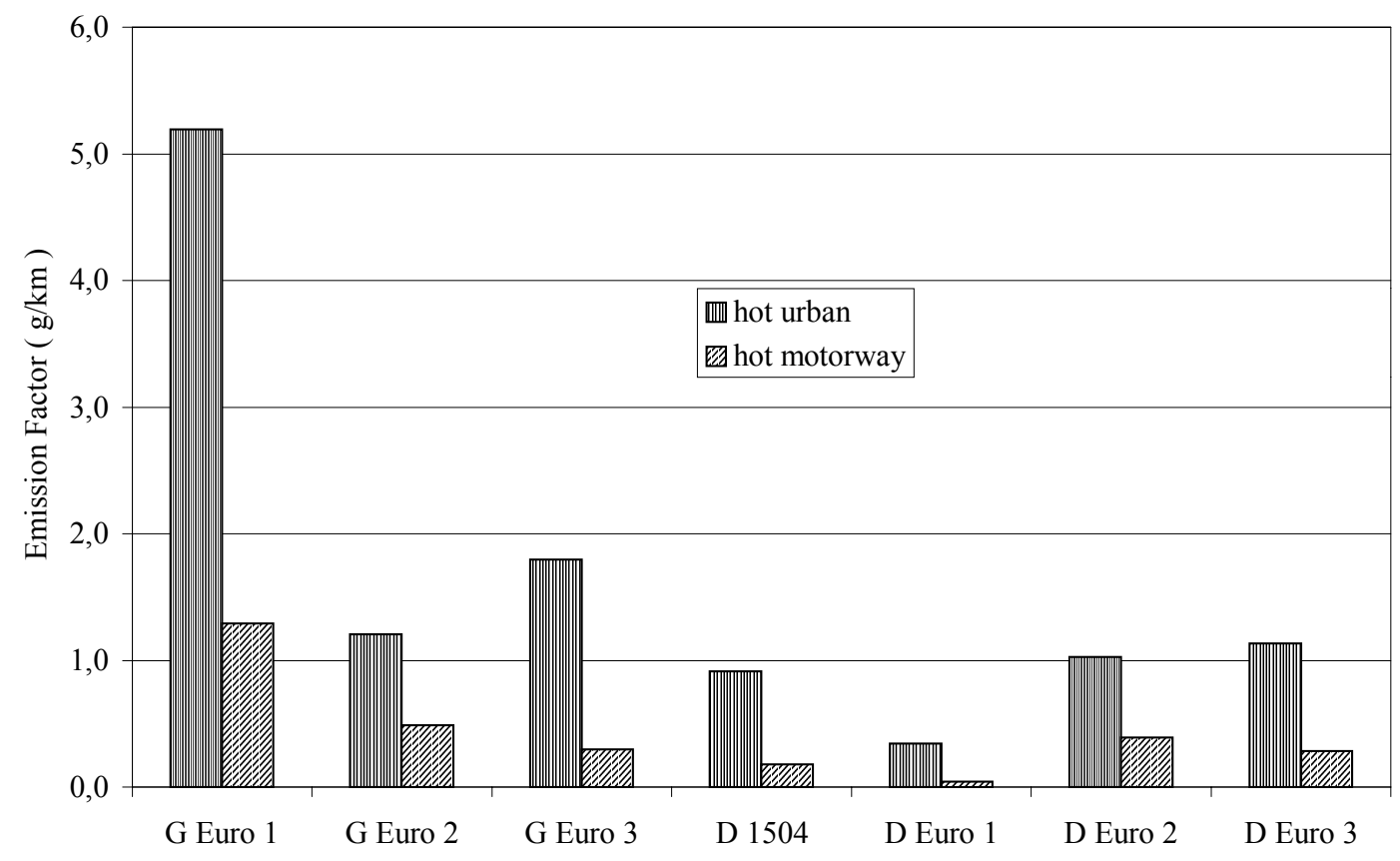

Figure 3: Average emission factors of the sum of VOC for hot "VP" urban vs motorway driving cycles $\left(\mathrm{g} \mathrm{km}^{-1}\right)$.

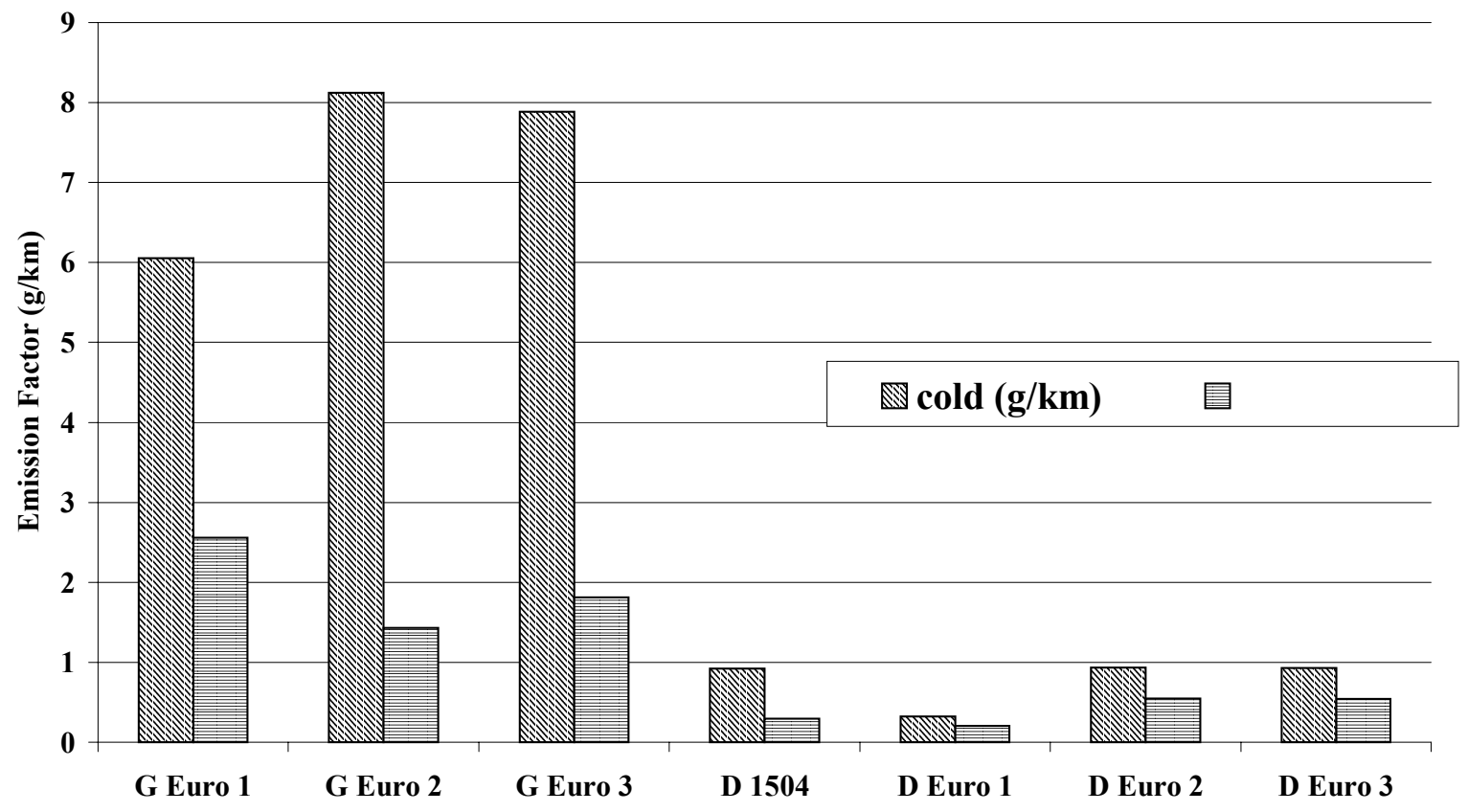

Figure 4: Average emission factors of the sum of VOC for cold vs hot 15xIUFC driving cycles (in $\mathrm{g} \mathrm{km}^{-1}$ ) 


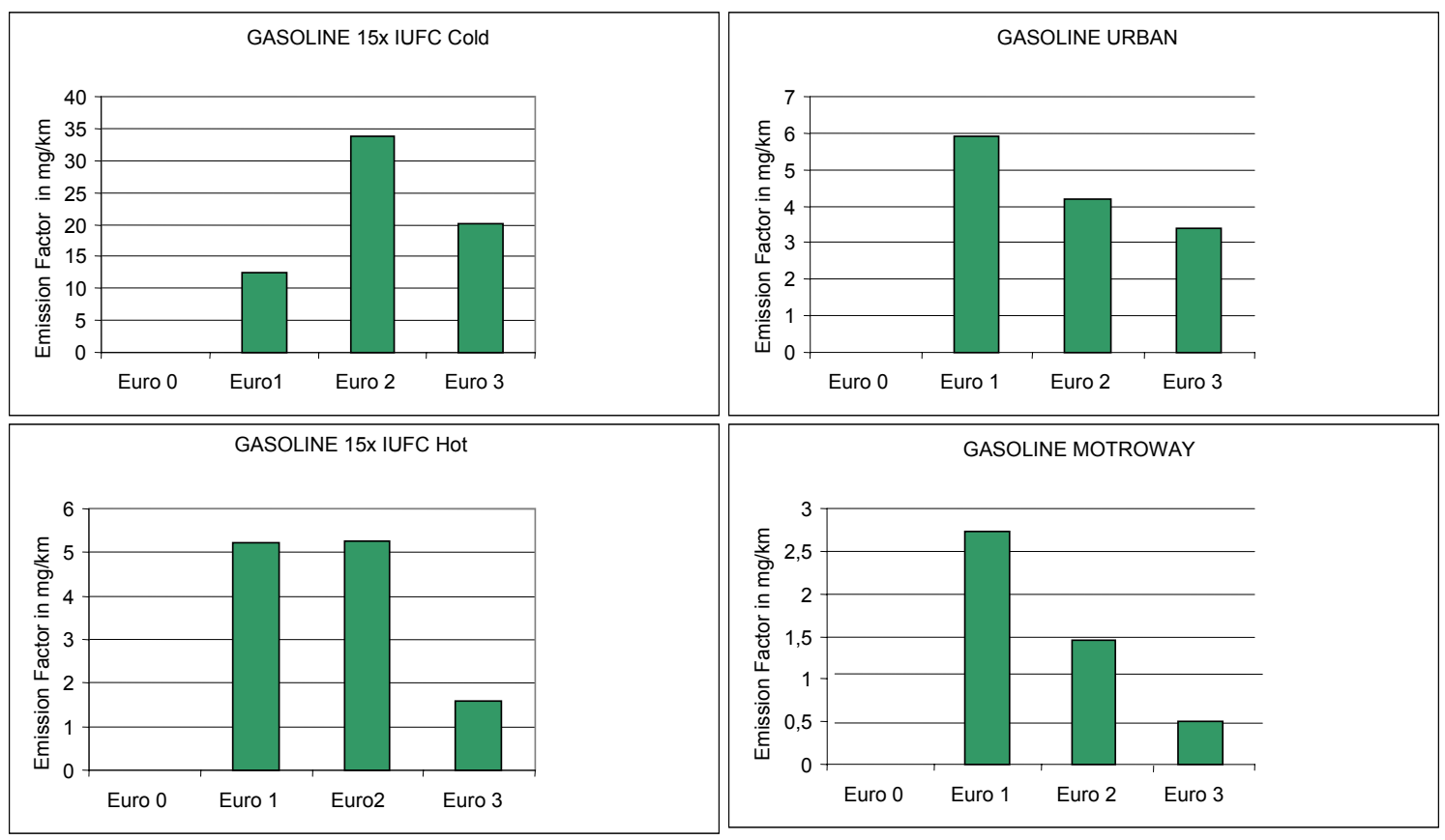

Figure 5: Emission factors of the aromatic compounds according to the European emission standard and the driving cycle for gasoline cars.
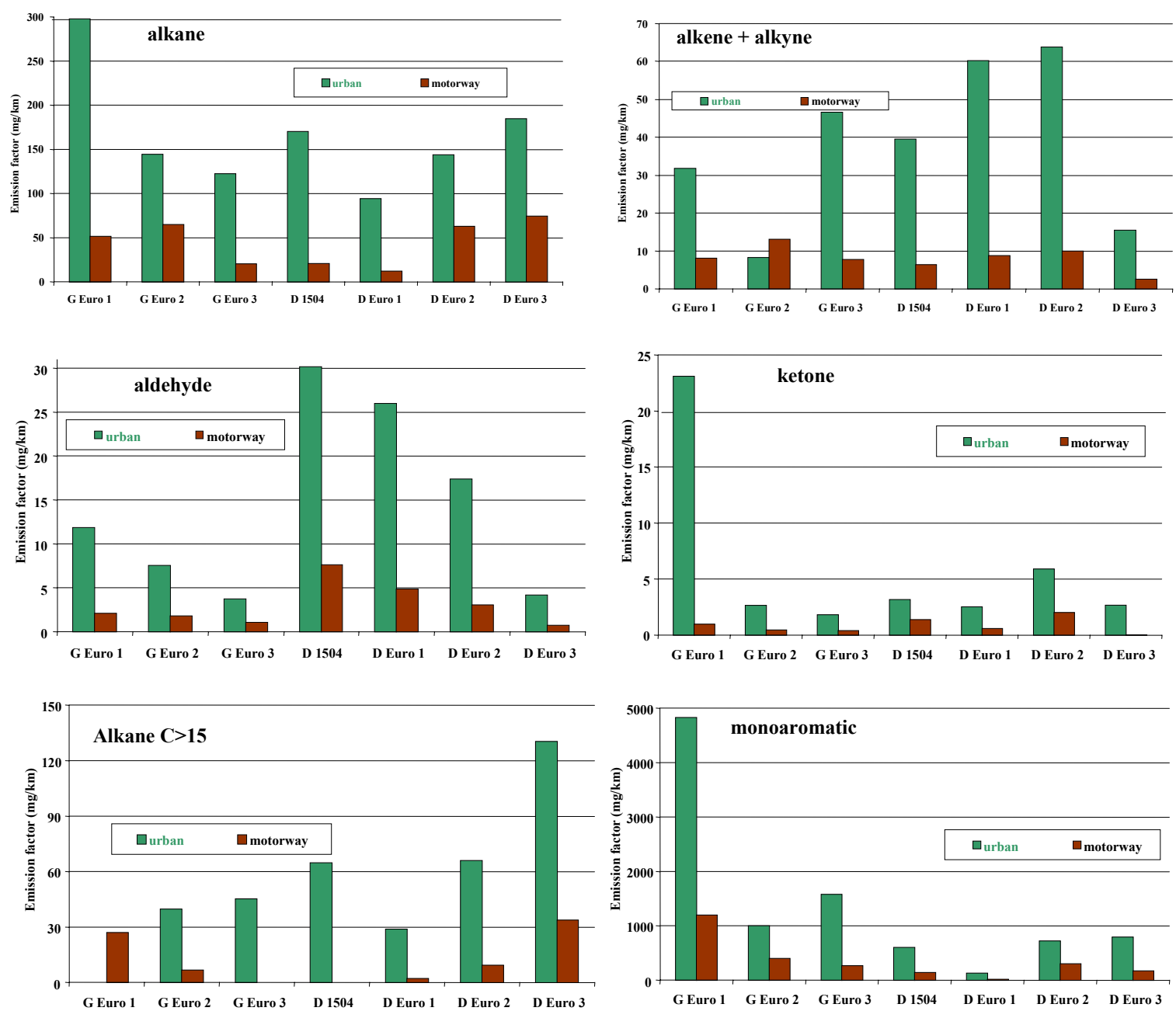

Figure 6: Evolution of the emission for the different compound families during "VP" urban and motorway driving cycles. 
Table:

Table 1: Distribution per fuel and emission standard of the sample of vehicles.

\begin{tabular}{|l|l|c|}
\hline \multicolumn{2}{|c|}{ Sample } & $\begin{array}{c}\text { Number of } \\
\text { vehicles }\end{array}$ \\
\hline \multirow{4}{*}{ Gasoline } & Euro 1 & $\mathbf{3}$ \\
\cline { 2 - 3 } & Euro 2 & $\mathbf{6}$ \\
\cline { 2 - 3 } & Euro 3 & $\mathbf{4}$ \\
\cline { 2 - 3 } & $\underline{\text { Total }}$ & $\underline{13}$ \\
\hline \multirow{5}{*}{ Diesel } & ECE 1504 & $\mathbf{2}$ \\
\cline { 2 - 3 } & Euro1 & $\mathbf{3}$ \\
\cline { 2 - 3 } & Euro 2 & $\mathbf{1 0}$ \\
\cline { 2 - 3 } & Euro 3 & $\underline{17}$ \\
\cline { 2 - 3 } & Total & \\
\hline
\end{tabular}

Table 2. The features of the driving cycles.

\begin{tabular}{|c|c|c|c|c|c|}
\hline Driving cycle & $\begin{array}{c}\text { Duration } \\
(\mathbf{s e c})\end{array}$ & $\begin{array}{c}\text { Length } \\
(\mathbf{m})\end{array}$ & $\begin{array}{c}\text { Mean speed } \\
\left(\mathrm{km} \mathrm{h}^{-1}\right)\end{array}$ & $\begin{array}{c}\text { Max. speed } \\
\left(\mathrm{km} \mathrm{h}^{-1}\right)\end{array}$ & Condition \\
\hline 15xIUFC & 2835 & 14985 & 19.037 & 44 & Cold, urban \\
\hline 15xIUFC & 2835 & 14985 & 19.037 & 44 & Hot, urban \\
\hline $\begin{array}{c}\text { VP low / high mot. } \\
\text { urban }\end{array}$ & $945 / 918$ & $4799 / 4924$ & $18.3 / 19.3$ & $55.7 / 57.6$ & Hot, urban \\
\hline $\begin{array}{c}\text { VP low / high mot. } \\
\text { motorway }\end{array}$ & $729 / 750$ & $24090 / 25377$ & $119.0 / 121.8$ & $150.7 / 157.1$ & $\begin{array}{c}\text { Hot, } \\
\text { motorway }\end{array}$ \\
\hline
\end{tabular}

Table 3: Flow rate sampling on the cartridges:

\begin{tabular}{|c|c|c|c|c|c|}
\hline Type of Cartridge & Tenax & Carbotrap & Carbotrap & 2,4 DNPH & 2,4 DNPH \\
\hline Driving Cycle & $\begin{array}{l}\text { All types of } \\
\text { cycles }\end{array}$ & 15xIUFC & VP & 15xIUFC & VP \\
\hline $\begin{array}{l}\text { Flow rate } \\
\text { ml min }^{-1}\end{array}$ & $\begin{array}{c}\text { From } 300 \text { to } \\
75 \\
\end{array}$ & From 100 to 25 & 100 & $\begin{array}{c}\text { From } 1200 \text { to } \\
600 \\
\end{array}$ & 1200 \\
\hline
\end{tabular}


Table 4 : Conditions for speciated analysis of hydrocarbon emissions

\begin{tabular}{lcc}
\hline Desorption conditions & TurbomatrixTD & Combi Injector / desorberEM640Brüker \\
\hline Cartridge temperature & $250^{\circ} \mathrm{C}$ & $\mathbf{2 2 0}^{\circ} \mathrm{C}$ \\
Desorption time & $7.5 \mathrm{~min}$ & $5 \mathrm{~min}$ \\
Cold trap temperature & $-30^{\circ} \mathrm{C}$ to $300^{\circ} \mathrm{C}$ (hold 1min) \\
Transfer line temperature & $\mathbf{2 0 0}^{\circ} \mathrm{C}$ & \\
\hline
\end{tabular}

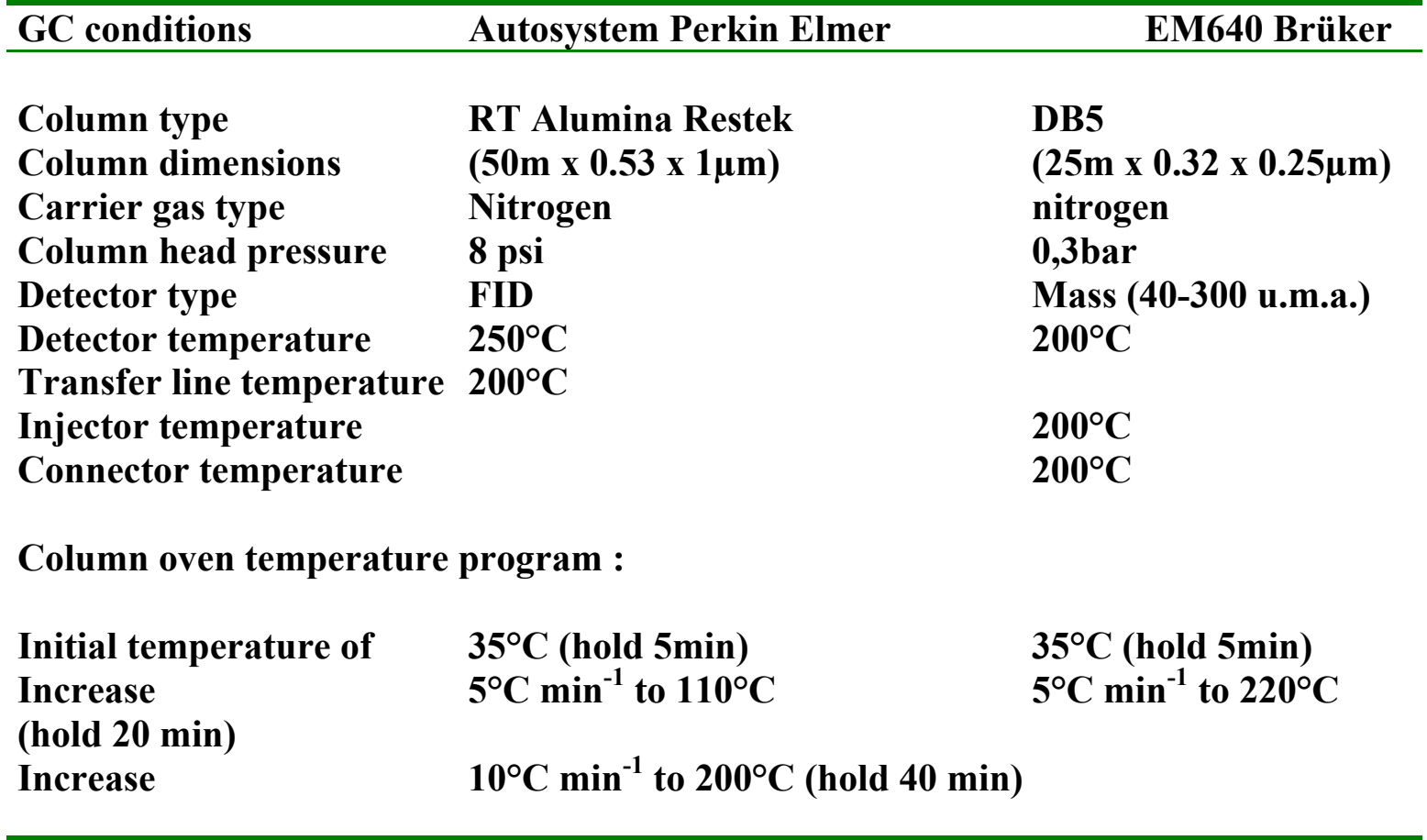

Table 5 : Compounds identified by GC/FID in the exhaust gas

\begin{tabular}{|l|l|l|}
\hline 1-butene & cis-1,2 dimethylcyclohexane & hexane \\
\hline 1-pentene & trans-1,2 dimethylcyclohexane & isobutene \\
\hline cis-2-butene & cis-1,4 dimethylcyclohexane & isopentane \\
\hline ethene & trans-1,4 dimethylcyclohexane & n-butane \\
\hline ethane & 2,2- dimethylpropane & n- heptane \\
\hline hexene & 2-methylpentane & n-pentane \\
\hline propene & 2-methylpropane & propane \\
\hline trans-2-butene & 3-methylpentane & 2,2 -dimethylbutane \\
\hline acetylene & cyclohexane & \\
\hline
\end{tabular}

Table 6: Compounds identified by GC/MS in the exhaust gas

\begin{tabular}{|l|l|l|}
\hline $1,2,3,5$ tetramethylbenzene & tridecane & pentadecane \\
\hline $1,2,4,5$ tetramethylbenzene & 1-methyl-3-propylbenzene & tetradecane \\
\hline $1,2,4$ trimethylbenzene & n-undecane & n-octane \\
\hline $1,2,5$ trimethylbenzene & 2-ethyltoluene & benzene \\
\hline 1,3 diethylbenzene & 3-ethyltoluene & ethylbenzene \\
\hline 1,3 -dimethyl-4-ethylbenzene & 4-ethyltoluene & isobutylbenzene \\
\hline 1,4 diethylbenzene & n-decane & propylbenzene \\
\hline 1,4 -dimethyl-2-ethylbenzene & n-dodecane & tert-butylbenzene \\
\hline
\end{tabular}




\begin{tabular}{|l|l|l|}
\hline 1-methyl-2-isopropylbenzene & n-hexadecane & toluene \\
\hline 1-methyl-4-isopropylbenzene & isopropylbenzene & 1-methylnaphtalene \\
\hline 1-methyl-2-propylbenzene & m-xylene + p-xylene & 2-methylnaphtalene \\
\hline n-nonane & o-xylene & naphtalene \\
\hline
\end{tabular}

Table 7: Conditions for speciated analysis of carbonyls compounds

\begin{tabular}{|c|c|c|c|c|}
\hline Solvents & Water & Acetonitrile & Tetrahydrofuran & Time \\
\hline Initial gradient elution & 44 & 35 & 21 & Hold 17 min \\
\hline Lineary increase & 24 & 55 & 21 & Over 2min \\
\hline Lineary increase & 44 & 35 & 21 & Over 1 min \\
\hline Final gradient elution & 44 & 35 & 21 & Hold 5 min \\
\hline
\end{tabular}

Table 8: Carbonyl compounds identified by HPLC in the exhaust gas with their minimum concentration

\begin{tabular}{|l|c|}
\hline Compounds & ${\text { Limit of detection }\left(\text { ng cartridge }^{-1}\right)}^{-1}$ \\
\hline Formaldehyde & $\mathbf{5}$ \\
\hline Acetaldehyde & $\mathbf{8}$ \\
\hline Acetone & 6 \\
\hline Acrolein & $\mathbf{8}$ \\
\hline Propionaldehyde & 9 \\
\hline crotonaldehyde & 11 \\
\hline 2-Butanone & $\mathbf{8}$ \\
\hline Methacrolein & 10 \\
\hline Butyraldehyde & 13 \\
\hline Benzaldehyde & 12 \\
\hline Valeraldehyde & 14 \\
\hline p-tolualdehyde & 9 \\
\hline Hexaldehyde & \\
\hline
\end{tabular}

Tableau 9: Minimum concentration for VOC

\begin{tabular}{|l|c|c|}
\hline \multicolumn{1}{|c|}{ Compounds } & $\begin{array}{c}\text { Limit of detection } \\
\text { ng cartridge }\end{array}$ & Methods \\
\hline Ethane to n-pentane & 5 to 15 & GC /FID \\
\hline $\begin{array}{l}1 \text { pentene to } \\
\text { 1,4-dimethylcyclohexane cis }\end{array}$ & 10 & GC /FID \\
\hline Aromatics & 3 to 12 & GC /MS \\
\hline Alkanes from $\mathbf{C}_{7}$ to $C_{15}$ & 25 & GC /MS \\
\hline
\end{tabular}

Tableau 10: Distribution of the different compounds for gasoline and diesel vehicles: Emission factor in $\mathrm{mg} \mathrm{km}^{-1}$ 


\begin{tabular}{|c|c|c|c|c|c|c|c|c|}
\hline & 15xIUFC & 15xIUFC & VP urban & VP mway & 15xIUFC & $15 x I U F C$ & VP urban & VP mway \\
\hline & cold & hot & hot & hot & cold & hot & hot & hot \\
\hline & \multicolumn{4}{|c|}{13 gasoline vehicles } & \multicolumn{4}{|c|}{17 diesel vehicles } \\
\hline aldehyde & 6,7 & 5,2 & 1,2 & $\mathbf{0 , 3}$ & 19,6 & 17,3 & 2,1 & 0,4 \\
\hline ketone & 1,7 & 2,5 & 6,4 & 0,1 & $\mathbf{3 , 7}$ & 3,1 & $\mathbf{8 , 0}$ & $\mathbf{0 , 7}$ \\
\hline alkene alkyne & 93,1 & 33,4 & 10,8 & 3,1 & $\mathbf{3 4 , 7}$ & 16,5 & $\mathbf{0 , 0}$ & 1,2 \\
\hline alkane & 447,0 & 213,4 & 16,3 & 5,3 & 135,9 & 108,0 & 7,6 & 2,5 \\
\hline alkane $\mathrm{C}>15$ & 8,4 & 2,7 & 20,8 & 8,1 & 27,9 & 44,9 & 17,8 & 4,1 \\
\hline monoaromatic & 6643,6 & 1574,8 & 273,2 & $\mathbf{5 5 , 9}$ & 664,5 & 325,6 & 43,7 & 13,5 \\
\hline polyaromatic & $\mathbf{0}$, & $\mathbf{0}$ & 0 & 0,1 & 1,9 & 1,2 & 1,7 & $\mathbf{0 , 0}$ \\
\hline TOTAL VOC & 7200,5 & 1832 & 328,7 & 72,9 & 888,2 & 516,6 & 80,9 & 22,4 \\
\hline
\end{tabular}

\section{Figures Captions:}

Figure 1. Chassis dynamometer with Constant Volume Sampling (CVS) with the scheme of the analysis for unregulated compounds

Figure 2 : Thermodesorption of cartridge follow by GC/FID analysis.

Figure 3 : Average emission factors of the sum of VOC for hot "VP" urban vs motorway driving cycles $\left(\mathrm{g} \mathrm{km}^{-1}\right)$.

Figure 4 : Average emission factors of the sum of VOC for cold vs hot 15xIUFC driving cycles (in $\mathrm{g} \mathrm{km}^{-1}$ )

Figure 5: Emission factors of the aromatic compounds according to the European emission standard and the driving cycle for gasoline cars.

Figure 6. : Evolution of the emission for the different compound families during "VP" urban and motorway driving cycles.

Tables:

Table 1: Distribution per fuel and emission standard of the sample of vehicles.

Table 2. The features of the driving cycles

Table 3: Flow rate sampling on the cartridges

Table 4 : Conditions for speciated analysis of hydrocarbon emissions

Table 5 : Compounds identified by GC/FID in the exhaust gas

Table 6: Compounds identified by GC/MS in the exhaust gas

Table 7: Conditions for speciated analysis of carbonyls compounds

Table 8 : Carbonyl compounds identified by HPLC in the exhaust gas with their minimum concentration

Tableau 9: Minimum concentration for VOC

Tableau 10: Distribution of the different compounds for gasoline and diesel vehicles:

Emission factor in $\mathrm{mg} \mathrm{km}^{-1}$ 